\title{
DESAFÍOS PARA LA CIUDADANÍA Y EL SISTEMA DE DERECHOS FUNDAMENTALES EN LA ERA DIGITAL
}

\author{
CHALLENGES FOR CITIZENSHIP \\ AND THE FUNDAMENTAL RIGHTS SYSTEM \\ IN THE DIGITAL AGE
}

CARlos ArCe JimÉNEZ
Universidad de Córdoba

Fecha de recepción: $15-10-20$

Fecha de aceptación: 24-9-21

Resumen: La ciudadanía, como instrumento político-jurídico para la titularidad y ejercicio de los derechos fundamentales, afronta serios desafíos en el contexto de la era digital y de la expansión global de las nuevas tecnologías. Estos retos se pueden calificar como sistémicos, ya que cuestionan estructuralmente el concepto de ciudadania, tanto en sus dimensiones subjetiva y objetiva como en las herramientas jurídico-formales que precisa para su desarrollo. En el presente artículo también analizamos las dificultades específicas que la digitalización y las nuevas tecnologías representan para derechos fundamentales clave en la perspectiva liberal de la ciudadanía y para el principio de igualdad material, así como las respuestas alternativas que desde las ciencias políticas y jurídicas se están alumbrando.

Abstract: Citizenship, as a legal and political instrument for the ownership and the exercise of Fundamental Rights, faces serious challenges in the context of the digital era and the global expansion of new technologies. These challenges can be named as systemic as they structurally question the concept of citizenship, both in its subjective and objective dimensions and in the legal tools that it requires for its development. This article also analyses the particular obstacles that the digitization and new technologies represent for Fundamental Rights, key in the liberal perspective of citizenship and for the principle of material equality, as well as alternative proposals from legal and political sciences.

ISSN: 1133-0937

DOI: https://doi.org/10.20318/dyl.2022.6520
DERECHOS Y LIBERTADES

Número 46, Época II, enero 2022, pp. 241-272 
Palabras clave: ciudadanía, digitalización, derechos fundamentales, libertad, principio de igualdad

Keywords: citizenship, new technologies, fundamental rights, digitization, principle of equality

I've seen things you people wouldn't believe...

Blade runner (1982). Ridley Scott (dir.)

\section{RETOS PARA LOS PILARES DE LA CIUDANÍA}

La ciudadanía, entendida como el concepto jurídico, político y social que determina las relaciones de derechos/deberes de la persona con la organización político-territorial y el ordenamiento jurídico a los que se halla vinculada, afronta retos y desafíos de gran calado derivados del impacto de las nuevas tecnologías y la digitalización a nivel global (y transversal).

La ciudadanía contemporánea, como cualquier otra institución políticojurídica, ha experimentado un proceso de construcción histórica que ha afectado tanto a sus dimensiones subjetiva y objetiva como a los instrumentos formales de los que se sirve para desplegar sus efectos desde las revoluciones liberales hasta nuestros días ${ }^{1}$. Sin embargo, la peculiaridad del "contexto tecnológico-digital" actual reside en que afecta de forma simultánea y con singular profundidad a los señalados pilares de la ciudadanía. En el presente apartado nos detendremos en cada uno de esos aspectos.

En "Blade runner", mítica película dirigida por Ridley Scott, donde de forma muy temprana y con maestría se planteaban las grandes cuestiones que a la Humanidad le podían plantear avances tecnológicos como la robótica o la inteligencia artificial, el "replicante" Roy Batty (interpretado por Rutger Hauer) le anunciaba al policía Rick Deckard (encarnado por Harrison Ford) que había visto "cosas que no creería". En la materia que nos ocupa, no sería necesario que nos visitara un androide visionario para explicarnos

Hemos tratado en profundidad el concepto de ciudadanía y su proceso de construcción histórica en C. ARCE, La ciudadanía en la era de la globalización: el reto de la inclusión, Ed. Ramón Areces, Madrid, 2009 y en C. ARCE, Los derechos politicos de los residentes extranjeros: la ciudadanía inclusiva, Defensor del Pueblo Andaluz, Sevilla, 2012.

DERECHOS Y LIBERTADES

ISSN: $1133-0937$

Número 46, Época II, enero 2022, pp. 241-272

DOI: https://doi.org/10.20318/dyl.2022.6520 
las profundas transformaciones sociales, políticas y jurídicas que conlleva la nueva realidad tecnológica. Para los que pertenecemos a la generación de "emigrantes digitales" nos basta realizar una mirada retrospectiva para caer en la cuenta de que muchos de los elementos de nuestra cotidianidad presente a 30 años vista no distarían mucho de presenciar "naves ardiendo más allá del cinturón de Orión".

\subsection{Perspectiva subjetiva}

Tal como hemos adelantado, la titularidad de la ciudadanía ha sufrido una profunda transformación. Ha existido una suerte de "proceso inclusivo" que facilitó el acceso a la ciudadanía plena a colectivos inicialmente excluidos, al superar algunas barreras formales como las patrimoniales, étnicas o de género, entre otras ${ }^{2}$. La era tecnológico-digital no es una excepción, y también ha alterado la dimensión subjetiva de la ciudadanía, pero de una forma diferente. Ya no consiste en la incorporación de nuevas capas sociales, sino que cuestiona la configuración tradicional de la propia persona como titular de la ciudadanía.

La digitalización transversal de la sociedad ha producido un desdoblamiento de la persona: mi "yo analógico" y mi "yo digital”. De esta manera se podría hablar de la necesidad de una nueva dimensión digital de la ciudadanía ${ }^{3}$. De la incontestable existencia del "yo digital" da cuenta el hecho de que en no pocas ocasiones su "nacimiento" se adelanta al del analógico: hace ya una década cerca del $25 \%$ de las personas no natas tenían alguna presencia en internet (porque sus progenitores han subido a redes sociales ecografías, resultados de pruebas de embarazo...). Esas cifras se disparan hasta el $81 \%$ antes de cumplir los dos años ${ }^{4}$.

En la misma línea, la proyección del titular de la ciudadanía se puede considerar que abarca también aquellos dispositivos electrónicos donde se almacenan datos personales, imprescindibles para el libre desarrollo de la

2 Otras persisten, como ostentar la nacionalidad del país en el que se reside. C. ARCE, Los derechos políticos de los residentes extranjeros... cit.

3 V. MORENTE, "Big data o el arte de analizar datos masivos. Una reflexión crítica desde los derechos fundamentales", Derechos y Libertades, núm. 41, 2019, pp. 225-260.

4 "Digital Birth: Welcome to the Online World", Informe elaborado por AVG Technologies. Disponible en: https://www.engadget.com/2010-10-08-study-finds-92-of-kids-areonline-by-age-2-baby-dating-site-va.html_(07/05/2021). 
personalidad y la construcción de la propia identidad ${ }^{5}$. Rodotà afirma que la "cualidad de lo humano" se extiende también a estas máquinas, reforzando la idea de las distintas configuraciones posibles de la persona titular de derechos fundamentales: analógica, digital o tecnológica ${ }^{6}$.

La citada dimensión digital de la ciudadanía debe ofrecer herramientas para que el "yo digital" pueda ejercer de forma adecuada sus derechos en los nuevos espacios que surgen para ello de la mano de las nuevas tecnologías. Los instrumentos que jurisprudencial, normativa y doctrinalmente se han ido construyendo al servicio del "yo analógico", tradicional titular de la ciudadanía, se revelan como inadecuados, ya que en ocasiones las aspiraciones y necesidades de ambas facetas de la persona pueden ser divergentes, o incluso aparentemente contradictorias. Volveremos sobre este particular en el próximo apartado.

Para la dimensión subjetiva de la ciudadanía en este contexto gana relevancia el concepto de "identidad personal". Toda persona aspira a construir de la forma más libre posible dicha identidad, esencial para el desarrollo de la personalidad y la interacción social. La proyección digital de la misma se ha convertido en una piedra angular en su configuración, siendo las redes sociales el ejemplo más evidente de ello. El Derecho ha tratado de dar respuesta a las necesidades de la identidad en el mundo digital. Destaca el denominado "derecho a la autodeterminación informativa" 7 , reconocido por la sentencia del Tribunal Constitucional (STC) 254/1993, que pretende dotar al individuo de la capacidad de controlar la información que sobre él circula en diferentes ámbitos, entre ellos el digital, ya que es la base sobre la que construir la proyección externa de su identidad.

Hay diversos factores que cuestionan la libre determinación de la identidad en la "red de redes". Podemos señalar la ruptura de la lógica lineal del tiempo propia del mundo analógico; pasado, presente y futuro conviven simultáneamente en internet, siendo además la memoria digital "infinita" 8 .

5 En este sentido es pionera la Sentencia Tribunal Constitucional alemán de $27 / 02 / 2008$, que considera inconstitucional la posibilidad de intervenir cualquier dispositivo implicado en la gestión de internet que contemplaban las leyes sobre los servicios de seguridad, creando un nuevo derecho fundamental a la integridad y reserva de los sistemas informativos tecnológicos. S. RODOTA, El derecho a tener derechos, Trotta, 2014, pp. 290-291.

6 S. RODOTÀ, El derecho a tener derechos... cit p. 292.

7 Afirmado de forma temprana por la jurisprudencia constitucional alemana (Sentencia BVerfGE 65, 1, de 15 de diciembre de 1983).

8 V. MORENTE, “Big data o el arte de analizar datos masivos... cit., p. 251. Como respuesta a esta ruptura surge el denominado "derecho al olvido". 
Otro de los elementos muy relevantes es la multiplicidad de espacios donde transitan los datos personales que configuran la identidad, en muchos casos escapando del control efectivo de la persona, en gran medida porque en el contexto de las nuevas tecnologías lo privado se construye en el espacio público. La identidad acaba "dispersándose", pudiendo llegar a ser "incognoscible" para el propio interesado, o en el otro extremo existe el riesgo de que se establezcan unas características "obligadas" de la misma para evitar el posible rechazo social a quiénes no se ajusten a esos requisitos ${ }^{9}$.

\subsection{Perspectiva objetiva}

También la dimensión objetiva de la ciudadanía afronta grandes retos en la era digital. Principalmente dos cuestiones se plantean en este ámbito: cómo afectan las nuevas tecnologías al ejercicio de los derechos fundamentales "tradicionales" y si es posible y/o necesario construir nuevos derechos que den respuesta a los citados desafíos. Trataremos el primer interrogante en el siguiente apartado, centrándonos brevemente en el segundo en el presente, con algunos ejemplos de una marcada relevancia en los últimos tiempos.

El derecho de acceso a la información, y más en concreto a estar informado de los asuntos de interés público, se puede considerar un contenido más de la libertad información del art. 20.1.d) de la Constitución española (CE). Sin embargo, las enormes posibilidades de gestión y acceso a información que facilita la digitalización global han hecho que se plantee la posibilidad de un derecho a la transparencia en lo concerniente a la gestión de los asuntos públicos. Por supuesto que se pueden incardinar los diferentes aspectos de la transparencia en la libertad de información y los derechos de participación política (art. $23 \mathrm{CE}$ ), pero la configuración propia que la misma ha ido adquiriendo en conexión con otros conceptos político-jurídicos emergentes como el de "gobierno abierto" hace sostenible la defensa de la independencia de la transparencia como derecho. En esta línea, la Ley 19/2013 de transparencia, acceso a la información y buen gobierno afirma en su exposición de motivos $^{10}$ :

\footnotetext{
S. RODOTÀ, El derecho a tener derechos...cit., pp. 292 y ss.

10 R. SERRA, "La opinión pública ante la vigilancia masiva de datos. El difícil equilibrio entre acceso a la información y seguridad nacional", UNED Revista de Derecho Político, núm. 92, 2015, pp. 73-118.
} 
La transparencia, el acceso a la información pública y las normas de buen gobierno deben ser los ejes fundamentales de toda acción política. Sólo cuando la acción de los responsables públicos se somete a escrutinio, cuando los ciudadanos pueden conocer cómo se toman las decisiones que les afectan, cómo se manejan los fondos públicos o bajo qué criterios actúan nuestras instituciones podremos hablar del inicio de un proceso en el que los poderes públicos comienzan a responder a una sociedad que es crítica, exigente y que demanda participación de los poderes públicos.

Incluso los avances en el campo de la genética pueden ofrecer nuevos contenidos del derecho a la información con aspiración de alcanzar ciertos niveles de autonomía. Al igual que ya existe un derecho a conocer el propio estado de salud (art. 4 Ley 41/2002), cada persona podría tener derecho a conocer la información sobre su mapa genético ${ }^{11}$.

Van surgiendo otros elementos vinculados a derechos fundamentales como a la intimidad, libertad de expresión u opinión que en el contexto digital ganan relevancia e incluso demandan un reconocimiento individualizado. Así, por ejemplo, la integridad y reserva de los sistemas informativos tecnológicos respecto al derecho a la intimidad, o el "derecho al anonimato" proclamado por el Tribunal Supremo de Israel en sentencia de 25/03/2010 como imprescindible para un adecuado ejercicio de las libertades de expresión e información en internet ${ }^{12}$.

La necesidad de un abordaje más global de esta realidad se va consolidando en los centros de decisión político-jurídica. El Gobierno de España ha elaborado en el año 2020 el Plan España Digital 2025, en el que desde un enfoque multidisciplinar se plantean estrategias para afrontar los retos que las nuevas tecnologías y la digitalización suponen para nuestro país en los próximos años. Entre las prioridades se encuentra contar para 2025 con una Carta de Derechos Digitales que garantice un adecuado ejercicio de los derechos fundamentales para toda la ciudadanía en el mundo digital, tanto a través de nuevos instrumentos para los derechos "tradicionales" como de la consolidación de otros derechos de nueva creación ${ }^{13}$.

11 J.M. MARTÍNEZ, "La generalización de los test genéticos y su incidencia en los derechos fundamentales", Revista Europea de Derechos Fundamentales, núm. 29, 2017, p. 254.

12 S. RODOTÀ, El derecho a tener derechos... cit., pp. 304 y ss.

13 Disponible en: https://www.lamoncloa.gob.es/presidente/actividades/Documents/2020/ 230720-Espa\% C3\% B1aDigital_2025.pdf(07/05/2021). 
Pero es el acceso a internet el posible derecho fundamental emergente vinculado a las nuevas tecnologías más consolidado ${ }^{14}$. En el ámbito del Derecho Internacional de los Derechos Humanos (DIDH), la Declaración de Ginebra de 2003 y la Declaración de Principios Túnez de 2005 afirman que el mismo se deriva directamente del art. 19 de la Declaración Universal de los Derechos Humanos (DUDH). Por su parte, la "Declaración conjunta sobre libertad de expresión e Internet" -2011- (Organización de las Naciones Unidas -ONU-, Organización para la Seguridad y la Cooperación en Europa -OSCE-, Organización de Estado Americanos -OEA- y Comisión Africana de Derechos Humanos y de los Pueblos-CADHP-) determina la obligación positiva de facilitar el acceso universal a Internet (apdo. $\mathrm{n}^{\circ} 6$ a). El Informe del Relator Especial sobre la promoción y protección del derecho a la libertad de opinión y de expresión a la Asamblea de Naciones Unidas el 16 de mayo del 2011 reclama políticas públicas para que Internet resulte ampliamente disponible, accesible y asequible para todos los sectores de la población. Como cierre la "Declaración conjunta Desafíos para la libertad de expresión en la próxima década" (ONU, OSCE, OEA y CADHP) -2019- califica al acceso y uso de internet como un derecho humano (apdo. $\mathrm{n}^{\circ} 2$ a). Se le considera como un derecho de carácter instrumental imprescindible para el adecuado ejercicio de otros derechos fundamentales de contenido sustantivo ${ }^{15}$ en el escenario de la globalización digital.

En el marco del Derecho comparado también se abre paso la consideración del acceso a internet como derecho fundamental. El Tribunal Supremo de los Estados Unidos (EEUU) en 1997 consideró que se le debía otorgar un nivel de protección similar al de la libertad de expresión (caso Reno vs ACLU), y el Consejo Constitucional francés estableció que el acceso a internet debe ser garantizado plenamente (sentencia ${ }^{\circ}$ 2009-580). En 2001 se introduce un nuevo artículo 5.2 en la Constitución griega que afirma el dere-

14 Lorenzo Cotino ha analizado con profundidad esta materia en los últimos años; usaremos como referencia en las próximas líneas sus principales trabajos al respecto. En concreto ver L. COTINO, "Las obligaciones del Estado: el nuevo derecho fundamental de acceso a internet y las garantías a partir de la redefinición de las clásicas libertades informativas", en VVAA, La responsabilidad del Estado por la utilización de las tecnologías de la información y la comunicación (TIC), Universidad Católica de Colombia, Bogotá, 2015, pp. 51-94 y L. COTINO, “Online-offline. Las garantías para el acceso a internet y para la desconexión, bloqueo, filtrado y otras restricciones de la red y sus contenidos", UNED. Revista de Derecho Político, núm. 108, 2020, pp. 13-39.

15 Libertades de expresión, opinión e información, participación política, derecho a la educación... 
cho de participar en la sociedad de la información. Desde el 2013 la Constitución mexicana proclama que El Estado garantizará el derecho de acceso a las tecnologías de la información y comunicación... incluido el de banda ancha e internet. (art. 6). A un nivel legal Estonia ${ }^{16}$ y Finlandia ${ }^{17}$ garantizan el acceso a internet a su ciudadanía.

En el ámbito de la UE, la Directiva 2002/22/CE (Directiva de servicio universal), proclama el acceso universal, pero sin configurarlo como un derecho subjetivo. La exposición de motivos del Reglamento (UE) 2015/2120 se acerca algo más a ello al señalar que Los usuarios finales deben tener derecho a acceder a información y contenidos... a través de su servicio de acceso a internet.

En lo concerniente al Derecho español, lo más relevante lo encontramos en las previsiones de los Estatutos de Autonomía de nueva generación. Destacan entre ellos los Estatutos valenciano y andaluz; el primero establece en su art. 19.2 que Queda garantizado el derecho de acceso de los valencianos a las nuevas tecnologías... y el segundo en su art. 34 que Se reconoce el derecho a acceder y usar las nuevas tecnologías... La propia formulación que de estos derechos hacen los textos estatutarios los sitúan en el mismo contexto que los principios rectores constitucionales en cuanto a su carácter programático y a su dependencia del desarrollo mediante legislación ordinaria. Esta perspectiva queda reforzada por la STC 247/2007, que considera que los nuevos derechos incluidos por los Estatutos de $2^{\mathrm{a}}$ generación no pueden ser considerados directamente como subjetivos y ejercitables judicialmente. El siguiente hito lo encontramos en la Ley Orgánica 3/2018 de protección de datos personales y garantía de los derechos digitales (LOPD 2018), cuyo art. 85 proclama un Derecho de acceso universal a Internet. Consideramos reseñable que se formule como derecho, sin embargo, la propia LOPD 2018 deja claro que en ningún caso podemos entender el acceso a internet como derecho fundamental, ya que excluye al art. 85 de los preceptos que tienen carácter orgánico dentro de ella (Disp. Final $1^{\mathrm{a}}$ ).

De lo expuesto hasta ahora podemos destacar que la tendencia general a la hora de reconocer jurídicamente el acceso a internet pone mayor acento en evitar la discriminación formal en el mismo que garantizarlo con un contenido prestacional ${ }^{18}$. Ello representa un serio hándicap en la lucha contra la

16 Art. 5 Ley de Telecomunicaciones (2000).

17 Ley del Mercado de Comunicaciones (2009).

18 La constitución mexicana, y en mayor medida las citadas leyes estonia y finlandesa pueden constituir una excepción.

DERECHOS Y LIBERTADES

ISSN: 1133-0937

Número 46, Época II, enero 2022, pp. 241-272

DOI: https://doi.org/10.20318/dyl.2022.6520 
desigualdad material que representa la brecha digital, que analizaremos en los siguientes apartados.

Con ello no se quiere decir que no existan riesgos relevantes para la igualdad formal en el acceso a internet. Concluimos este apartado haciendo una breve alusión a uno de ellos: el cuestionamiento del principio de neutralidad de la red. Por neutralidad se entiende que todos los usuarios y contenidos deben tener un acceso equitativo y un trato igualitario en el tráfico de la red ${ }^{19}$; por razones comerciales los proveedores de internet presionan para romper, o al menos matizar, este principio y poder priorizar tanto en el acceso como en la velocidad en el tráfico a sus clientes más rentables económicamente. Por razones obvias minar la neutralidad de la red incrementa exponencialmente el peligro de discriminación respecto a los usuarios más vulnerables y a aquellos contenidos que, pudiendo alcanzar la mayor relevancia desde múltiples puntos de vista, tengan un menor valor comercial.

\subsection{Herramientas formales y técnicas para el ejercicio de la ciudadanía}

Junto a las analizadas dimensiones subjetiva y objetiva de la ciudadanía, no son de menor importancia para la efectividad de los derechos fundamentales a ella vinculados las herramientas formales y técnicas disponibles para su ejercicio. En el presente apartado nos detendremos en tres que a nuestro juicio tienen un gran protagonismo en la globalización digital: el Big data, los perfiles y los algoritmos.

\subsubsection{Big data}

Con este término hacemos alusión a dos realidades diferentes: a la ingente cantidad de datos que sobre las personas se pueden obtener y tratar en el actual contexto digital, por una parte, y a las herramientas tecnológicas que lo hacen posible, por otra. Algunos de estos datos son facilitados de forma voluntaria por sus titulares en sus múltiples interacciones en la red, pero otro gran porcentaje de esa información se extrae de nuestra estela digital detectada por diferentes dispositivos rastreadores de forma ajena a nuestra voluntad y consentimiento. Y, por supuesto, tanto la acumulación como la

19 Este principio está reconocido, entre otros, por el apdo. $5^{\circ}$ de la Declaración conjunta sobre libertad de expresión e Internet -2011- (ONU, OSCE, OEA y CADHP), por al art. 3 del Reglamento UE 2015/2120 y el art. 80 LOPD 2018. 
gestión de esos datos no es neutra ni aséptica para la indemnidad de los derechos fundamentales ${ }^{20}$.

Una de las principales aplicaciones del Big data es la elaboración de perfiles a partir de los cuales se pueden tomar decisiones sobre materias muy sensibles para la persona afectada. Volveremos sobre los perfiles en el siguiente apartado.

El Big data proyecta diferentes peligros. Morente destaca los derivados de su opacidad, ya que es muy difícil conocer con precisión el "quién, cómo y cuándo" del proceso de obtención de los datos que lo alimentan y también los conectados a su "inconmensurabilidad", dado el enorme volumen datos que de cada individuo se acumulan y la multiplicidad de actores implicados en su tratamiento ${ }^{21}$. Igualmente se pone de relieve que los "macrodatos" del Big data tienen serias dificultades para ofrecer una análisis objetivo e imparcial sobre la materia de que se trate, muy especialmente cuando se aplica al ámbito individual ${ }^{22}$.

Se plantea como solución facilitar una mayor información al afectado sobre la recogida de información y el tratamiento que se hace de ella a través de las herramientas del Big data. Quizás con ello se palía en cierta medida el citado riesgo de la opacidad, pero el aluvión de datos que representaría podría vaciar de contenido material el consentimiento que la persona otorgara ${ }^{23}$. De hecho, toda la construcción en materia de protección de datos tiene como base el consentimiento informado, algo que se empieza a ver seriamente cuestionado por elementos como el Big data ${ }^{24}$. En realidad, no es una situación muy diferente a la que tuvo que afrontar el tradicional consentimiento civil-mercantil con el advenimiento de los contratos de adhesión y los clausulados generales de la contratación.

Tal como señalamos, el ámbito de la investigación científico-médica es uno donde las posibilidades que ofrece el Big data tienen una mayor inci-

20 A. GARRIGA, "La elaboración de perfiles y su impacto en los derechos fundamentales. Una primera aproximación a su regulación en el reglamento general de protección de datos de la Unión Europea", Revista Derechos y Libertades, núm. 38, 2018, pp. 107-139.

21 V. MORENTE, “Big data o el arte de analizar datos masivos... cit., pp. 235-236.

22 F. MONTALVO, "Una reflexión desde la teoría de los derechos fundamentales sobre el uso secundario de los datos de salud en el marco del Big Data", UNED. Revista de Derecho Político, núm. 106, 2019, pp. 43-75.

23 V. MORENTE, “Big data o el arte de analizar datos masivos... cit., p. 237.

24 F. MONTALVO, “Una reflexión desde la teoría de los derechos fundamentales... cit., p. 55. 
dencia. Existe una tensión entre la protección de la intimidad individual y el interés general que representan los avances en materia de salud pública que se pueden derivar del uso masivo de datos por parte de la ciencia médica. Ello pone en el punto de mira el principio general de exigencia del consentimiento informado para cualquier tratamiento de datos de carácter personal. El Reglamento UE 2016/679 y la LOPD 2018 matizan ese principio para la investigación médica, permitiendo el uso secundario de datos personales al servicio del interés general y la salud pública sin necesidad de un nuevo consentimiento expreso, siempre que sean "seudonimizados". Algunos autores sin embargo consideran imprescindible dar un paso más en este campo, suprimiendo incluso la necesidad de contar con ese consentimiento previo inicial, garantizando eso sí la plena “anonimización" de los datos ${ }^{25}$.

\subsubsection{Perfiles}

Una de las principales aplicaciones del Big data es la elaboración de "perfiles", definidos por el art. 4.4 del Reglamento (UE) 2016/679 como:

toda forma de tratamiento automatizado de datos personales consistente en utilizar datos personales para evaluar determinados aspectos personales de una persona física, en particular para analizar o predecir aspectos relativos al rendimiento profesional, situación económica, salud, preferencias personales, intereses, fiabilidad, comportamiento, ubicación o movimiento de dicha persona fisica

La utilización de estos perfiles en la toma de decisiones que afectan a los derechos fundamentales de las personas hace que se deba ser exigente con la calidad de los datos que se utilizan y con la transparencia en el procedimiento de su elaboración. Coincidimos con Garriga en señalar que, junto a la amenaza para la intimidad, estos perfiles representan el peligro de reforzar estereotipos negativos que afectan a ciertos colectivos, ahondando en su situación de exclusión. En general, puede decirse que inciden notoriamente en el control de la propia identidad del interesado ${ }^{26}$.

En la configuración de los perfiles tienen un papel protagónico los omnipresentes "algoritmos", que otorgan a los primeros el halo exactitud y neu-

25 F. MONTALVO, “Una reflexión desde la teoría de los derechos fundamentales...cit., p. 67.

26 A. GARRIGA, “La elaboración de perfiles y su impacto en los derechos fundamentales...cit., pp. 130 y ss. 
tralidad que se le suele asignar a lo matemático, que en muchas ocasiones no se corresponde a la realidad. No son infrecuentes tanto los errores materiales directos derivados de malas praxis en la obtención de datos o de conclusiones inexactas, como los sesgos "estructurales" que se introducen en los perfiles y en los algoritmos sobre los que se elaboran ${ }^{27}$.

Ante esta tesitura, el art. 22 Reglamento (UE) 2016/67928 garantiza que:

Todo interesado tendrá derecho a no ser objeto de una decisión basada únicamente en el tratamiento automatizado, incluida la elaboración de perfiles, que produzca efectos jurídicos en él o le afecte significativamente de modo similar.

Esta contundente afirmación queda muy matizada por las amplias excepciones contenidas en el mismo precepto, ya que estas decisiones automatizadas (basadas en su mayoría en perfiles) se pueden producir en el contexto de las relaciones contractuales, cuando lo contemple el Derecho de la Unión Europea (UE) o de los Estados miembros (con una genérica alusión a medidas de protección de los derechos fundamentales) o mediando el consentimiento expreso de la persona afectada. También se establece en el art. 22 una prohibición especial para el perfilado y la toma de decisiones automatizadas que se basen en los datos sensibles contemplados por el art. 9 del reglamento (los que hacen referencia a la ideología, creencias, biometría, a la genética/salud y a la vida/orientación sexual), aunque de nuevo cuenta con excepciones no menores (concurrencia del consentimiento del interesado o de un "interés público esencial").

No compartimos la idea de que el perfilado con fines comerciales o de marketing sea inocuo desde la perspectiva ético-jurídica, ya que igualmente puede afectar directa o indirectamente al derecho a la intimidad y a la protección de datos personales del afectado si no se respetan los principios básicos del Reglamento UE 2016/679 y la LOPD 2018 en su elaboración. Por el contrario, tenemos la misma inquietud que muchos autores respecto a la gran peligrosidad que representan los perfiles que incluyen los datos sensibles del citado art.9 del reglamento para la dignidad de la persona en general y el principio de igualdad en particular ${ }^{29}$. Algunas iniciativas tomadas en al actual contexto de la pandemia que "perfilan" sobre datos sanitarios inciden a nuestro juicio en esos riesgos.

27 V. MORENTE, “Big data o el arte de analizar datos masivos...cit., p. 238.

28 Con el antecedente del art. 15 de la Directiva 95/46/CE.

29 V. MORENTE, “Big data o el arte de analizar datos masivos...cit., p. 242.

DERECHOS Y LIBERTADES

ISSN: 1133-0937

Número 46, Época II, enero 2022, pp. 241-272

DOI: https://doi.org/10.20318/dyl.2022.6520 


\subsubsection{Algoritmos}

Cerramos este apartado con una referencia a los algoritmos, pieza clave en el binomio ciudadanía-nuevas tecnologías que estamos analizando en el presente artículo. En palabras de Rodotà, en el mundo digital la construcción de la identidad queda sustraída de la autonomía de la voluntad del sujeto, quedando entregada por completo a los algoritmos ${ }^{30}$. En la misma línea, la confluencia entre Big data y algoritmos puede cuestionar el propio concepto de privacidad ${ }^{31}$.

Nos parecen muy pertinentes las reflexiones de Boix Palop sobre el carácter normativo de los algoritmos ${ }^{32}$, que analizamos a continuación. Dada la apariencia puramente técnica de la materia, existe la tentación de dejar su configuración a la autorregulación de los agentes privados que intervienen en la "industria del algoritmo", ya que al fin y al cabo son "los que entienden" de una cuestión meramente tecnológica en teoría ajena a lo jurídico.

Sin embargo, hemos comprobado que nada más lejos de la realidad, ya que los algoritmos intervienen de forma directa en la toma de decisiones con consecuencias jurídicas sobre la ciudadanía. Sería aplicable la premisa kelseniana respecto a que a la hora de definir una norma como jurídica prima el contenido materialmente normativo respecto a la dimensión formal. Por lo tanto, es lógico que se exijan procedimientos y garantías similares a las de las "normas analógicas" en la creación de estas "normas digitales". Desgraciadamente, por el momento tanto en el ámbito de la UE como en el español se está lejos de esta perspectiva, y tan solo a través de la regulación en materia de transparencia se puede tener acceso en determinados casos a conocer los algoritmos en sí y a los programas informáticos utilizados en su elaboración, lo que tan solo cubre algunos de los aspectos del procedimiento normativo.

Andrés Boix presta especial atención a la utilización de estas herramientas normativo-tecnológicas en las relaciones de la Administración con la ciudadanía, y defiende que los algoritmos y sus "códigos fuente" deben ser con-

30 S. RODOTA, El derecho a tener derechos...cit., p. 307.

31 P. TUCKER, “¿Han hecho los grandes volúmenes de datos que el anonimato sea imposible?", MIT Technology Review, 16/05/2013, traducción de Francisco Reyes (OPINNO). Disponible en: https://www.technologyreview.es/negocios/43072/han-hecho-los-grandes-volumenesde-datos-que-el/ (07/05/2021)

32 A. BOIX, "Los algoritmos son reglamentos: la necesidad de extender las garantías propias de las normas reglamentarias a los programas empleados por la administración para la adopción de decisiones", Revista de Derecho Público: Teoría y Método, vol. 1, 2020, pp. 223-269.

ISSN: 1133-0937

DOI: https://doi.org/10.20318/dyl.2022.6520
DERECHOS Y LIBERTADES

Número 46, Época II, enero 2022, pp. 241-272 
siderados como reglamentos, siéndoles de aplicación por tanto los requisitos generales de elaboración de normas reglamentarias previstos en el Título VI de la Ley de Procedimiento Administrativo Común de las Administraciones Públicas (Ley 39/2015). De esta manera estaría vigente el principio de publicidad íntegra, se garantizaría la participación ciudadana, tendrían que respetarse con plenitud los nuevos requerimientos en materia de transparencia y estaría abierta la opción de los recursos directos o indirectos de los que pueden ser objeto los reglamentos.

Y no estamos ante disquisiciones futuristas de ciencia ficción. Por ejemplo, desde el año 2007 se encuentra en marcha el Sistema de Seguimiento Integral de los casos de Violencia de Género (Ministerio del Interior) ${ }^{33}$ que, en base a los datos que sobre la materia recopila y analiza, a través de un algoritmo realiza predicciones sobre potenciales amenazas delictivas de este perfil. Y en el contexto de la pandemia de la COVID-19, el Ministerio de Asuntos Económicos y Transformación Digital ha lanzado la aplicación Radar-COVID ${ }^{34}$, que de nuevo mediante algoritmos evalúa posibles riesgos de contagios. Tanto por la sensibilidad de los datos manejados como por las consecuencias derivadas de estas herramientas para los derechos fundamentales, las garantías arribas expuestas para el proceso de su elaboración y aplicación se revelan como imprescindibles.

\section{LA DIMENSIÓN LIBERAL DE LA CIUDADANÍA EN UN MUNDO DIGITALIZADO ${ }^{35}$.}

Llama la atención que sea la dimensión liberal de la ciudadanía (en la que se incardinan los derechos civiles y políticos), la más consolidada político-jurídicamente, la principalmente afectada por la revolución tecnológicodigital. Analizaremos esta circunstancia a través de algunos de los derechos fundamentales sobre los que se sostiene la misma.

33 http://www.interior.gob.es/web/servicios-al-ciudadano/violencia-contra-la-mujer/sistema-viogen $(07 / 05 / 2021)$.

34 https://www.mineco.gob.es/portal/site/mineco/menuitem.ac30f9268750bd56a0b0240e026041a0/?vgnextoid=359f50a4c34b3710 VgnVCM1000001d04140aRCRDEvgnextchannel=864e154527515310VgnVCM1000001d04140aRCRD (07/05/2021).

35 Una completa visión del impacto de las nuevas tecnologías en la ciudadanía y democracias liberales en J.M. LASSALLE, Ciberleviatán: El colapso de la democracia liberal frente a la revolución digital, Arpa Editores, Madrid, 2019. 


\subsection{Derecho a la intimidad, al honor y a la propia imagen}

El derecho a la intimidad se ha definido tradicionalmente como el "derecho a estar solo" o "a ser dejado en paz". Se vincula con la existencia de un espacio íntimo propio al que solo pueden tener acceso los terceros autorizados por el titular en el uso de su autonomía personal. El advenimiento de las nuevas tecnologías ha incidido en el bien jurídico protegido "intimidad" en dos aspectos: surgen nuevos peligros para el mismo que demandan herramientas jurídicas innovadoras para su protección ${ }^{36}$; y la propia esencia del concepto muta desde una perspectiva básicamente negativa (protección frente al "tercero curioso indeseado") a otra mucho más proactiva (control en la gestión de mi privacidad, que ya no en todo caso se desea esconder de la mirada ajena) ${ }^{37}$.

En la mutación del concepto de intimidad tiene un protagonismo singular el descrito desdoble entre "yo analógico" y "yo digital". A nuestro juicio, en las relaciones sociales en las que no intervienen las nuevas tecnologías todavía se mantienen algunas demandas no tan alejadas del "derecho a estar solo", mientras que en el ámbito digital la tendencia es a compartir voluntariamente aspectos muy íntimos, reclamando para ello instrumentos de gestión, no de exclusión. Estas diferentes expectativas, en gran medida contradictorias, pueden generar tensiones y disfunciones en la respuesta jurídica para la protección del bien jurídico que nos ocupa.

Las redes sociales son un ejemplo paradigmático de los nuevos retos. Los usuarios vuelcan de forma compulsiva y masiva información personal sin conocer (por falta de posibilidad material y/o interés) el destino final o el uso secundario que se puede hacer de la misma ${ }^{38}$. Por otra parte, el control de la privacidad no solo implica al titular original de los datos que se comparten, sino que también involucra a todas las personas con las que interactúa en las redes sociales ${ }^{39}$. A pesar de los retos derivados del nuevo contexto digital, la jurisprudencia constitucional sigue afirmando que debe existir en él una "expectativa razonable de confidencialidad", aunque evidentemente dicha expec-

36 Algo que ya intuyó el constituyente español al incluir el apdo. $4^{\circ}$ al art. $18 \mathrm{CE}$.

37 J. MARTÍNEZ DE PISÓN, "Vida privada sin intimidad. Una aproximación a los efectos de las intromisiones tecnológicas en el ámbito íntimo", Derechos y Libertades, núm. 37, 2017, pp. 51-84.

38 L. FLORES, "Facebook y el derecho a la propia imagen: reflexiones en torno a la STC 27/2020, de 24 de febrero", Revista Estudios de Deusto, vol. 68 núm. 1, 2020, pp. 335-376.

39 A. GARRIGA, "La elaboración de perfiles y su impacto en los derechos fundamentales... cit., p. 121. 
tativa se modulará en función de la herramienta tecnológica utilizada: no es lo mismo un mensaje privado remitido persona-persona a través de una aplicación de mensajería, que un "post" en un chat de acceso público ${ }^{40}$.

Ante estas circunstancias, el Derecho empezó a reaccionar de forma temprana con la afirmación de la existencia de un derecho a la "autodeterminación informativa" (STC 254/1993), que tiene una vertiente "defensiva" (contemplada en el art. 18.4 CE, con esa primitiva alusión a la limitación del uso a la informática) y otra proactiva que haría referencia al citado control efectivo de los datos.

Pronto se vio desbordada la "autodeterminación informativa" por el incesante y vertiginoso desarrollo de las nuevas tecnologías, y como consecuencia de ello se alumbró la protección de datos de carácter personal como derecho fundamental independiente, que tuvo su consagración como tal en el art. 8 de la Carta de Derechos Fundamentales de la Unión Europea (CDFUE) en el ámbito europeo, con el antecedente de la Directiva 95/46/CE y el posterior desarrollo mediante el Reglamento (UE) 2016/679. En España, los hitos normativos y jurisprudenciales clave fueron la primigenia LOPD (LO 15/1999), la STC 292/2000 y la vigente LOPD 2018. Los instrumentos básicos para la protección de los datos de carácter personal son los denominados derechos ARCO (acceso, rectificación, cancelación y oposición) ${ }^{41}$, que se vieron completados con el "derecho al olvido" ${ }^{42}$. El Reglamento (UE) 2016/679 trata de reforzar la exigencia a los proveedores de servicios digitales de mayores esfuerzos directos y preventivos en la protección de la intimidad, ya que seguir centrando la misma principalmente en el consentimiento informado se ha mostrado como muy insuficiente ${ }^{43}$.

Por razones obvias el derecho a la propia imagen es otro de los especialmente concernidos en el mundo digital. Muy vinculado con el de intimidad, es un derecho fundamental autónomo ${ }^{44}$ que otorga a su titular la facultad

40 Ver SSTC 241/2012 y 170/2013. L. COTINO, “Las obligaciones del Estado: el nuevo derecho fundamental de acceso a internet... cit., p. 75.

41 J. MARTÍNEZ DE PISÓN, “Vida privada sin intimidad. Una aproximación a los efectos... cit., pp. 65 y ss.

42 Reconocido jurisprudencialmente por el Tribunal de Justicia de la Unión Europea (TJUE) en sentencia de 13 de mayo de 2014 (C-131/12) y plasmado normativamente por el art. 17 Reglamento UE 2016/679 y los arts. 93-94 LOPD 2018.

43 V. MORENTE, “Big data o el arte de analizar datos masivos... cit., p. 248.

44 Amplia jurisprudencia del TC ha ido estableciendo la configuración constitucional de este derecho: SSTC 231/1988, 99/1994, 117/1994, 81/2001, 83/2002; 14/2003; 72/2007; $176 / 2013$, entre otras. 
de controlar la captación y difusión de la información sobre los rasgos (físicos, voz, nombre...) que identifican a una persona. De nuevo en el uso de la propia imagen por terceros el consentimiento se establece como clave de bóveda, incidiendo desde su origen por las propias características del bien jurídico protegido más en el control que en la exclusión.

El derecho fundamental con el que tradicionalmente entra en conflicto el derecho a la propia imagen es la libertad de información. La jurisprudencia del TC ha establecido la preponderancia de esta última siempre que concurra un "interés social" en el contenido informativo en el que se use la imagen (STC 19/2014). En esta línea ya el art. 8.2 LO 1/1982 dispensaba de la concurrencia del consentimiento para la utilización de la imagen de los "personajes públicos" captadas en actos o lugares igualmente públicos, así como de su caricatura. Tampoco hace falta el consentimiento de personas sin esa relevancia pública si su imagen aparece con carácter accesorio en un contenido informativo.

Tal como hemos destacado, en el mundo digital ha crecido exponencialmente la exposición de la propia imagen, singularmente en las redes sociales. Consideramos relevante en este aspecto la reciente STC 27/2020 referente a la utilización por parte de un medio de comunicación de una imagen compartida por un usuario en la red social Facebook para ilustrar una noticia sin su consentimiento. Hay algunos aspectos muy interesantes en esta sentencia.

Respecto al consentimiento, el TC afirma que el hecho de compartir una imagen en una red social no conlleva una especie de consentimiento tácito para que se pueda usar libremente por terceros fuera del contexto de esa red y sus condiciones de uso (art. 2.2 LO 1/1982 exige un consentimiento "expreso") ${ }^{45}$. A la hora de valorar la posible concurrencia de las excepciones contempladas en el art. 8.2 LO 1/1982 en estos casos, no las descarta de forma general la sentencia, aunque no las considerara aplicables al supuesto de hecho concreto objeto de la misma. Por último, también a los efectos del art 8.2 LO 1/1982, el TC afirma que una red social no puede considerarse "un lugar abierto al público", espacios donde es posible atenuar el vínculo directo entre consentimiento y uso de la imagen por un tercero ${ }^{46}$.

45 El máximo intérprete constitucional afirma que ese consentimiento tácito no se podría inferir ni siquiera de la aceptación de las frecuentemente genéricas, poco comprensibles e incluso abusivas políticas de privacidad de la mayoría de redes sociales.

46 Un completo análisis de la sentencia en L. FLORES, “Facebook y el derecho a la propia imagen...cit. 


\subsection{Libertad de expresión e información}

No hay duda de que, potencialmente, las libertades de expresión e información pueden ser los derechos fundamentales más beneficiados de la digitalización y las nuevas tecnologías. Pero al mismo tiempo corren unos riesgos específicos en este contexto.

En lo que afecta a la libertad de expresión se podrían destacar diversos abordajes. Por supuesto, la era digital ofrece poderosas herramientas a los Estados que no cumplen los estándares democráticos mínimos para ejercer la censura y la represión del ejercicio de aquellos derechos fundamentales que tienen en el medio digital un nuevo cauce instrumental fundamental ${ }^{47}$. Partiendo de la indudable relevancia de la dimensión estatal, nos parece igualmente necesario destacar el creciente papel que juegan los agentes privados en este ámbito, básicamente las empresas proveedoras de los distintos servicios imprescindibles para interactuar en internet ${ }^{48}$. Hay que tener en cuenta que los grandes instrumentos del DIDH no establecen obligaciones directas para las empresas en materia de Derechos Humanos; los documentos existentes al respecto tienen un marcado carácter programático y "softlaw" 49.

El papel de las empresas va más allá del rol predominante que le da el monopolio material de la infraestructura de la "red de redes", ya que incluso intervienen en la determinación de la regulación en esta materia, especialmente en lo que tiene que ver con las normas "técnicas" y las políticas sectoriales ${ }^{50}$.

En ocasiones las propias empresas rechazan la responsabilidad excesiva que desde los Estados se les otorga para controlar el cumplimiento de la legisla-

47 Con la imposición de bloqueos o filtros, cierres de sitios web, desconexión de usuarios...Ver "Informe del Relator Especial sobre la promoción y protección del derecho a la libertad de opinión y de expresión”, Frank La Rue. Consejo de Derechos Humanos. $17^{\circ}$ período de sesiones 16/05/2011. Disponible en: https://undocs.org/es/A/HRC/17/27 (07/05/2021).

48 Ver "Informe del Relator Especial sobre la promoción y protección del derecho a la libertad de opinión y de expresión" David Kaye. Consejo de Derechos Humanos. $32^{\circ}$ período de sesiones 11/05/2016, al que hacemos referencia en las siguientes líneas. Disponible en: https://undocs.org/es/A/HRC/32/38 (07/05/2021).

49 Por todos los "Principios rectores sobre las empresas y los Derechos Humanos". Alto Comisionado Derechos Humanos ONU. 2011.

$(07 / 05 / 2021)$.

https://www.ohchr.org/documents/publications/guidingprinciplesbusinesshr_sp.pdf

50 P.ej., La Unión Internacional de Telecomunicaciones participa en la construcción de las políticas de telecomunicaciones globales.

DERECHOS Y LIBERTADES

ISSN: 1133-0937

Número 46, Época II, enero 2022, pp. 241-272

DOI: https://doi.org/10.20318/dyl.2022.6520 
ción aplicable a la libertad de expresión/opinión. Una de las prácticas con más impacto en este aspecto es la del filtrado y bloqueo de contenidos potencialmente ilícitos, ya que se está poniendo en manos privadas la limitación material de derechos fundamentales. En otros supuestos son las políticas internas de los proveedores de servicios las que establecen bloqueos arbitrarios muy cercanos a la simple censura ${ }^{51}$. Ya indicamos la relevancia de mantener la neutralidad de la red para el ejercicio en el mundo digital de los derechos fundamentales en general, y de la libertad de expresión particular, y las presiones de las empresas del sector en sentido contrario, por lo que damos aquí por reproducidas las consideraciones hechas en su momento. Por último, hay que señalar que los mecanismos internos que ofrecen los proveedores de servicios digitales para reparar los daños infligidos a la libertad de expresión de sus usuarios dejan mucho que desear, siendo las vías alternativas de reclamación (judiciales o arbitrales) onerosas en tiempo y dinero e inciertas en su resultado material práctico.

En resumen, los tradicionales parámetros establecidos por el DIDH para considerar como legítima la limitación de la libertad de expresión ${ }^{52}$, quedan distorsionados por la intervención de estos agentes privados en su ejercicio en el mundo digital.

La libertad de información tiene un doble contenido: el derecho de transmitir libremente la información, vinculado históricamente al ejercicio profesional del periodismo, por una parte, y el derecho de la ciudadanía a acceder también libremente a una información veraz. Aunque se puede afirmar que los principios básicos de este derecho fundamental siguen vigentes en el mundo digital, las nuevas tecnologías plantean retos tanto en el plano objetivo como en el subjetivo. En la primera perspectiva destaca el cambio de las coordenadas de espacio-tiempo; en cuanto al espacio determina que cualquier información pueda tener potencialmente alcance global gracias al fenómeno de la "viralización", mientras que el tiempo se debate entre la caducidad inmediata vinculada al aluvión inabarcable e ininterrumpido de información y la "vida eterna" que puede tener una noticia en el mundo digital. En este sentido nos parece muy interesante la idea de un "derecho al

51 En este sentido ha sido ampliamente cuestionada la práctica de la red social "Instagram" de bloquear imágenes donde aparezcan pezones femeninos desnudos, permitiendo sin embargo aquellas que muestran pezones masculinos. Ver Normas Comunitarias de Instagram: https://help.instagram.com/477434105621119 (07/05/2021).

52 Entre otros ver el art. 19.3 del Pacto Internacional de Derechos Civiles y Políticos (PIDCP) y la sentencia del Tribunal Europeo de Derechos Humanos (STEDH) en el caso núm. 6538/74, The Sunday Times v. The United Kingdom (26/04/1979). 
contexto" que acompañe a la información y la preserve de las distorsiones derivadas de los desafíos de las nuevas tecnologías ${ }^{53}$.

Teniendo en cuenta la conexión directa entre la libertad de información y la profesión periodística, hemos de destacar la revolución que ha supuesto la irrupción del "ciberperiodismo" en este ámbito. Ha modificado profundamente la praxis profesional por la combinación de diversos factores: priorización de la inmediatez sobre la calidad de la información, precarización laboral y pérdida de peso de la tradicionales "cabeceras de referencia" con la proliferación de nuevos medios digitales. Por otro lado, ha permitido el ascenso del "periodismo ciudadano", donde la ciudadanía pasa de mera receptora pasiva de la noticia a intervenir de forma proactiva en su creación y difusión.

Esta nueva realidad para el ejercicio de la libertad de información tiene una indiscutible vertiente positiva en la medida que refuerza el pluralismo y la democratización del espacio informativo. Sin embargo, el deterioro del rigor que conlleva la pulsión por la inmediatez y la precarización laboral, unida a la intervención de actores no profesionales, puede poner en riego al derecho a recibir una "información veraz" ${ }^{54}$ que asiste al ciudadano (art. 20.1 d) CE). Por otra parte, aunque se ha afirmado que la libertad de información no es patrimonio exclusivo de los periodistas ${ }^{55}$, sí que se otorga una protección reforzada a la profesión periodística y a los medios de comunicación por su rol protagonista en la formación de la opinión pública, herramienta clave para el sistema democrático ${ }^{56}$. Consideremos que no hay grandes dificultades para extender esa protección de mayor rango a las nuevas formas de hacer periodismo, incluidos los medios de comunicación emergentes que tienen una configuración muy diferente a los tradicionales. Genera dudas por el contrario que sin más se le pueda aplicar al "periodismo ciudadano" cuando se ejerce fuera de cualquier estructura profesional ${ }^{57}$. Quizás esa realidad tenga todavía un mejor encaje en la libertad de expresión.

53 R.M. GARCÍA, “La difícil relación del instituto de la opinión pública y los procesos de comunicación pública en internet: la desinformación desafiando las garantías constitucionales", UNED. Revista de Derecho Político, núm. 106, 2019, pp. 77-104.

54 Hay que tener en cuenta que "información veraz" no es sinónimo de verdad objetiva: «lo que ampara el art. 20.1 d) es la información rectamente obtenida y difundida, aun cuando su total exactitud sea controvertible» (STC 121/2002, de 20 de mayo, F $^{\circ}$ J $^{\circ}$. 5).

55 STC 6/1981 y STEDH Youth Iniciative for Human Rights vs. Serbia de 25/06/2013.

56 SSTC 165/1987 y 105/1990.

57 J. de MIGUEL "Las transformaciones del derecho de la información en el contexto del ciberperiodismo", Revista de Estudios Políticos, núm. 173, julio/septiembre 2016, pp. 141-168. 
Otras cuestiones vinculadas al mundo digital afectan de forma intensa a la libertad de información, cuyo tratamiento detallado se escapa a la acotada extensión de este texto. Simplemente hacer alusión al creciente peso de la inteligencia artificial en este campo, tanto por el hecho de que comienza a estandarizarse la elaboración automatizada de noticias de determinado perfil (meteorológicas, deportivas...) como la intervención de la misma en la creación y difusión de las "noticias falsas" y en la manipulación informativa ${ }^{58}$. O como en el reconocimiento del nuevo "derecho al olvido", cuando interacciona con la libertad de información, se ha protegido la fuente original de la información (la hemeroteca del medio de comunicación donde originalmente se recoge la noticia), imponiendo las restricciones a los "buscadores", que son los que en realidad pueden introducir la distorsión temporal que trata de corregir el citado derecho ${ }^{59}$.

\subsection{Derechos de participación}

La digitalización tampoco ha pasado de largo de la participación ciudadana. Tal como indicamos para otros derechos, en el contexto de las nuevas tecnologías podemos afrontar esta materia desde diversas perspectivas, pero nos interesa especialmente aquella que está vinculada a la libertad de información que acabamos de analizar.

Una de las funciones constitucionales de la libertad de información es la configuración de la "opinión pública", imprescindible para que el valor superior "pluralismo político" proclamado por el art 1.1 CE sea efectivo. Algunos autores señalan que un internet verdaderamente libre sería una herramienta muy valiosa para la construcción de la opinión pública, pero consideran que ha sido una oportunidad perdida por la inacción de los Estados y el predominio de los intereses privados de las empresas del sector ${ }^{60}$.

El nuevo marco tecnológico ha transformado profundamente el espacio público-político $^{61}$, que en la actualidad se caracteriza por el predominio de

58 J.L. MANFREDI y M.J. UFARTE, “Inteligencia artificial y periodismo: una herramienta contra la desinformación", Revista CIDOB d'Afers Internacionals, núm. 124, (abril de 2020), pp. 49-72.

59 Ver Sentencia TJUE C-131/12, de 13/05/2014, y STS 545/2015, de 15/10/2015.

60 R.M. GARCÍA, “La difícil relación del instituto de la opinión pública... cit., pp. 95-96.

61 Es básico en esta materia el predominio de lo audiovisual en la configuración de la opinión pública y su correspondiente impacto en el espacio político y en la participación ciudadana. Ver G. SARTORI, Homo videns: La sociedad teledirigida, Taurus, Madrid, 1998. 
lo afectivo sobre lo racional y por una pronunciada polarización. En ello las redes sociales han tenido un papel protagónico. Los partidos políticos tradicionales ven peligrar su papel "mediador" hegemónico en este ámbito y se refuerzan los hiperliderazgos personales. La emotividad empuja hacia la búsqueda de la reafirmación de los posicionamientos de partida y el sentimiento de grupo, minando la reflexión y la deliberación; más que convencer racionalmente al votante se pretende influenciar en sus sensaciones y percepciones $^{62}$. Estamos en la época de la "posverdad", donde la opinión o el "relato" sobre la realidad tiene una mayor relevancia que los hechos que la constituyen ${ }^{63}$. Por lo expuesto, se impone la polarización haciendo muy difícil el debate transaccional, esencial para la democracia.

La utilización de la desinformación ${ }^{64}$ y la manipulación como herramienta política es casi consustancial a la organización de la sociedad humana como comunidad. No era otra cosa lo que criticaba Sócrates a los sofistas. El gran cambio reside en el efecto multiplicador que sobre la desinformación tienen instrumentos como las redes sociales ${ }^{65}$. El peligro de las "noticias falsas" ${ }^{66}$ no está en que sean prueba de la existencia de la mentira en el espacio público, ya que incluso hay quien afirma que la acción de mentir en realidad forma parte de la libertad de expresión (con los límites inherentes a cualquier derecho fundamental, evidentemente) y que la democracia no es un régimen que busque una verdad objetiva científicamente constatable. El riesgo se encuentra en la incapacidad de discernir lo real de la falacia manipuladora, y eso es lo que precisamente facilita el nuevo contexto tecnológico con su aluvión de información sin filtro ni contexto, poniendo en cues-

62 M. ARIAS, “La digitalización de la conversación pública: redes sociales, afectividad política y democracia", Revista de Estudios Políticos, núm. 173, 2016, pp. 27-54.

63 C. PAUNER, "Noticias falsas y libertad de expresión e información. El control de los contenidos informativos en la red", UNED. Teoría y Realidad Constitucional, núm. 41, 2018, pp. 297-318.

64 Entendemos por desinformación en el mundo digital la creación, producción y distribución de informaciones falsas, imprecisas o descontextualizadas, así como la captura de información privada (perfiles y prácticas en redes sociales) con fines propagandísticos y la creación de perfiles y usuarios falsos para operaciones de influencia. J.L. MANFREDI y M.J. UFARTE, "Inteligencia artificial y periodismo... cit., p.51.

65 D. INNERARITY y C. COLOMINA, "La verdad en las democracias algorítmicas", Revista CIDOB d'Afers Internacionals, núm. 124, 2020, pp. 11-23.

66 Informaciones publicadas deliberadamente en medios digitales que no han sido comprobadas ni verificadas, carecen de fuentes identificadas y sin supervisión de un editor. Su objetivo es influir en la opinión pública y crear inseguridad, sospechas, desestabilización para apoyar o desacreditar o, a veces, simplemente diversión. C. PAUNER, “Noticias falsas y libertad de expresión... cit.,pp. 300-301.

DERECHOS Y LIBERTADES

Número 46, Época II, enero 2022, pp. 241-272
ISSN: 1133-0937

DOI: https://doi.org/10.20318/dyl.2022.6520 
tión la confianza de la ciudadanía en el correcto funcionamiento del sistema democrático ${ }^{67}$.

Los algoritmos y perfiles también sirven de catalizador en la expansión y consolidación de la desinformación. En el primer aspecto porque los ítems que tienen en cuenta los algoritmos de buscadores y redes sociales para viralizar contenidos suelen coincidir con las características esenciales de las noticias falsas ${ }^{68}$. Los perfiles por su parte construyen para cada individuo una suerte de "caja de resonancia reafirmante" donde solo ingresan contenidos políticos-ideológicos afines al mismo, lo que dotará de una mayor apariencia de veracidad a informaciones que serían notoriamente dudosas fuera de ese marco filtrado tendenciosamente de partida ${ }^{69}$.

En los países democráticos ha empezado a ser una prioridad la lucha contra la desinformación. Se tratan de poner medidas técnicas y humanas de "fact checking" de carácter público y privado para localizar y neutralizar las noticias falsas, y también empiezan a tomarse algunas medidas legislativas al respecto. Hay que buscar un delicado equilibrio entre prevenir la desinformación y no cuestionar las libertades de expresión e información ${ }^{70}$.

En el ámbito de la UE se ha propuesto implicar a las empresas proveedores de servicios de internet en esta materia a través de la aprobación de un Código de prácticas autorreguladoras sobre la desinformación ${ }^{71}$, aprobado en octubre 2018. Consideramos que este tipo de iniciativas no son las más adecuadas, primero porque los intereses de estas empresas miran su objetividad e imparcialidad, así como por la poca pertinencia de dejar en manos privadas decisiones que pueden afectar directa o indirectamente a derechos fundamentales. Dos Estados miembros de la UE han aprobado recientemente en su Derecho interno normas específicas contra la desinformación.

67 V.Y. GARCÍA, “Donde habitan las mentiras: libertades de expresión e información en tiempos de odio e hiperinformación", Revista CIDOB d'Afers Internacionals, núm. 124, 2020, pp. 25-47.

68 D. INNERARITY y C. COLOMINA, "La verdad en las democracias algorítmicas", cit., p.21.

69 C. PAUNER, “Noticias falsas y libertad de expresión... cit., pp. 303-304.

70 R.M. GARCÍA, "La difícil relación del instituto de la opinión pública...cit., pp. 81-82. En este sentido el TJUE ha advertido contra el uso masivo e indiscriminado de sistemas de filtrado o bloqueo, incluso cuando se alegue la defensa de otros derechos: SSTJUE C-70/10, Scarlet c. SABAM, de 24 de noviembre de 2011, C-360/10, Netlog c. SABAM, de 16 de febrero de 2012 y Internet STJUE C-314/12, caso Telekabel, de 27 de marzo de 2014.

71 https://ec.europa.eu/digital-single-market/en/news/code-practice-disinformation $(07 / 05 / 2021)$.

ISSN: 1133-0937

DOI: https://doi.org/10.20318/dyl.2022.6520
DERECHOS Y LIBERTADES

Número 46, Época II, enero 2022, pp. 241-272 
Alemania aprobó la Ley de aplicación de la red en 2018, que obliga a las plataformas en línea a retirar en un plazo de 24 horas desde la recepción de la denuncia de un usuario contenidos considerados como discurso de odio, noticias falsas o delictivos, incluyendo fuertes sanciones económicas para aquéllas que no se avengan a hacerlo. En el caso de Francia, también en 2018 se aprobó la Ley relativa a la lucha contra las falsas informaciones, que en el contexto de los procesos electorales permite suprimir de forma inmediata los contenidos calificados como desinformación mediante orden judicial. En el caso de España, todavía no se ha desarrollado ninguna iniciativa normativa específica sobre la materia ${ }^{72}$.

Por último, hay que destacar aquellos aspectos en los que las nuevas tecnologías pueden ofrecer oportunidades para las herramientas de participación ciudadana. En esta línea señalar la Recomendación del Comité de Ministros del Consejo de Europa a los Estados miembros sobre la democracia electrónica (CM/Rec $-2009-1)^{73}$ y la Resolución del Parlamento Europeo, de 16 de marzo de 2017, sobre la democracia digital en la Unión Europea: posibilidades y retos (2016/2008 -INI-) ${ }^{74}$. Ambos documentos alientan a los Estados a fomentar la "e-democracia", ya que consideran que con ella se aumentan las oportunidades de la ciudadanía de acceso a la información sobre asuntos públicos, de rendición de cuentas de las instituciones y de participación más directa. Junto a esas oportunidades coinciden en advertir de las dificultades específicas para el principio de igualdad material que también conlleva la e-democracia, a las que nos referiremos en el siguiente apartado. Dentro de las opciones a desarrollar llama especialmente la atención el "voto electrónico a distancia", por afectar a la herramienta por antonomasia de la democracia representativa, el derecho de sufragio. En Estonia desde el año 2007 existe esta posibilidad en sus procesos electorales ${ }^{75}$.

72 R. MAGALLÓN, “La (no) regulación de la desinformación en la Unión Europea. Una perspectiva comparada”, UNED. Revista de Derecho Político, núm. 106, septiembre-diciembre 2019, pp. 319-347.

73 https://www.coe.int/t/dgap/goodgovernance/Activities/Key-Texts/Recommendations/ Recommendation_CM_Rec2009_1_en_PDF.pdf(07/05/2021).

74 https://www.europarl.europa.eu/doceo/document/TA-8-2017-0095_ES.pdf(07/05/2021).

75 M.Á. PRESNO, "Premisas para la introducción del voto electrónico en la legislación electoral española” ${ }_{\llcorner}$Revista de Estudios Políticos, núm.173, 2016, pp. 277-304. 


\section{NUEVAS TECNOLOGÍAS Y PRINCIPIO DE IGUALDAD MATERIAL}

Hemos puesto de relieve en anteriores apartados que uno de los mayores desafíos que afronta la ciudadanía en un mundo tecnológico y digitalizado está relacionado con el principio de igualdad material. Realmente no podemos decir que sea un reto exclusivo de las nuevas tecnologías, pero sí que desde su consolidación toma otra dimensión.

En este contexto se habla principalmente de la "brecha digital", concepto que analizaremos de inmediato. Sin embargo, la quiebra de la igualdad material empieza en aspectos previos a la tecnología digital. En el año 2015 todavía había unos 1.200 millones de personas en el planeta sin acceso a la electricidad; por ejemplo, en las zonas rurales de África subsahariana la tasa de electrificación apenas llega al 17\%. La Agencia Internacional de la Energía consideraba en 2015 altamente improbable que se consiguiera en 2030 el objetivo de desarrollo sostenible de un acceso universal a energías asequibles y limpias, ya que en esa fecha tan solo estaba comprometido el 5\% de la inversión necesaria estimada para ello ${ }^{76}$. Sin garantizar la disponibilidad de energía eléctrica, el acceso a las nuevas tecnologías se convierte una quimera, y con ello quedan vedadas las formas de ejercicio de los derechos fundamentales a ellas vinculadas.

Por brecha digital se puede entender la separación existente entre aquellas personas y grupos que tienen acceso material a las nuevas tecnologías y a los conocimientos-habilidades imprescindibles para su utilización, y aquellas que no lo tienen ${ }^{77}$. Hay que tener en cuenta que estamos ante un concepto poliédrico y multidimensional, y desde esa perspectiva debe ser analizado.

Como hemos destacado, una de las características de la gobernanza del mundo digital es la escasa intervención estatal y el papel protagonista del "mercado" y los agentes privados que en él operan. Desde un punto de vista global, éste es un escenario abonado para ahondar la brecha digital entre países de altos y bajos ingresos ${ }^{78}$.

76 A. PUEYO, “El acceso universal a una energía asequible, fiable, sostenible y moderna", Colección monografias CIDOB, 3/2017, Objetivos de desarrollo sostenible, pp. 35-48.

77 S. OLARTE "Brecha digital, pobreza y exclusión social", Revista Temas Laborales, núm. 138, 2017, pp. 285-313 y L. COTINO, “Las obligaciones del Estado: el nuevo derecho fundamental...cit., p. 58 .

78 Declaración de principios de la Cumbre de la Sociedad de la Información, ONU, 2003: https://www.itu.int/net/wsis/docs/geneva/official/dop-es.html\#: :text=Nosotros\%2C\%20los\%20representantes \%20de\%20los,Informaci\% C3\% B3n\%20centrada\%20en\%20la\%20persona\%2C (07/05/2021).

ISSN: 1133-0937

DOI: https://doi.org/10.20318/dyl.2022.6520
DERECHOS Y LIBERTADES

Número 46, Época II, enero 2022, pp. 241-272 
Otro ejemplo de lo poliédrico de la "exclusión digital" lo podemos encontrar en la invisibilización que sufren los colectivos y realidades sociales subalternas. Los algoritmos que rigen el Big data los condenan al ostracismo de los "márgenes tecnológicos", relegando a un segundo plano sus necesidades, intereses y aspiraciones ${ }^{79}$.

En realidad, la brecha digital es, por una parte, una consecuencia de las desigualdades sociales previas, y por otra, es causa de que dichas desigualdades se profundicen y perpetúen. En este sentido se puede hablar de brecha digital de género, generacional, territorial... para destacar como las nuevas tecnologías en gran medida trasladan las tradicionales exclusiones del mundo analógico al digital ${ }^{80}$.

Algunos datos nos pueden ayudar a contextualizar la vinculación entre pobreza y exclusión digital. Según la Encuesta de Condiciones de Vida de 2019 (Instituto Nacional de Estadística -INE-) ${ }^{81}$, más de una cuarta parte de la población residente en España está en riesgo de pobreza $(25.3 \%$, tasa AROPE). Este riesgo aumenta de forma sensible para las personas menores de 16 años (30.1\%), extranjeras de terceros países no UE (54.2\%) y residentes en Andalucía o Extremadura (37.7\%). Poniendo en relación estas cifras con las de la Encuesta sobre Equipamiento y Uso de Tecnologías de Información y Comunicación en los Hogares de 2019 (INE) ${ }^{82}$, podemos encontrar alguna conexión reveladora. Teniendo como referencia ese $25 \%$ de riesgo de pobreza en España, vemos que un $22 \%$ de las personas residentes en España no usa internet a diario, el 19\% de los hogares no poseen los dispositivos electrónicos más vinculados al ámbito laboral o educativo (ordenador o tablet) y el 15\% no dispone de acceso a banda ancha de internet en su modalidad fija. También es llamativo que sea el territorio de España con una menor tasa de riesgo de pobreza (Navarra, 11.7\%) el que tiene un mayor porcentaje de usuarios de internet (95\%). No sería muy aventurado establecer un nexo causa-efecto entre ambas realidades.

Hay que destacar que menos del $40 \%$ de los residentes en España tiene unas "habilidades digitales avanzadas", circunstancia en la que puede influir tanto el riesgo de exclusión como la brecha generacional. Respecto a

\footnotetext{
79 V. MORENTE, “Big data o el arte de analizar datos masivos...cit., pp. 228-229.

80 S. OLARTE "Brecha digital, pobreza y exclusión social”... cit., pp. 292-293 y L. COTINO, “Las obligaciones del Estado: el nuevo derecho fundamental...cit., p. 58.

81 https://www.ine.es/prensa/ecv_2019.pdf(07/05/2021).

82 https://www.ine.es/prensa/tich_2019.pdf(07/05/2021).
} 
esta última, es reseñable que el acceso regular a internet entre jóvenes de 16 a 24 años es prácticamente pleno (99.1\%), porcentaje que se desploma en casi 76 puntos a partir de los 74 años (23.4\%). Afortunadamente constata el INE que el sesgo de género prácticamente ha desaparecido desde la perspectiva del acceso a la red, aunque se mantiene en cierta medida en lo concerniente a las actividades realizadas en la misma: las mujeres muestran mayor interés en temas sanitarios y sociales o en interactuar en las redes sociales, mientras que los hombres acceden más a contenidos informativos y a espacios online de compra-venta de bienes y servicios.

La generalización de las relaciones de la ciudadanía con la Administración vía electrónica es uno de los aspectos donde la digitalización transversal está generando nuevas grietas de desigualdad ${ }^{83}$. En el estudio del INE que estamos usando como referencia se señala que más del 63\% de los encuestados ha realizado trámites ante una institución pública por internet. El 11.3\% de ellos señalan que no pudieron concluir la gestión, y es fácil de inferir que en el 37\% que ni siquiera lo intentaron estarán sobrerrepresentadas las personas de mayor de edad y las que se encuentran en riesgo de exclusión social ${ }^{84}$.

En la situación derivada de la pandemia del coronavirus se han intentado reforzar las vías telemáticas de ejercicio de derechos fundamentales como alternativa, con una singular incidencia en el derecho a la educación. Ello ha evidenciado el peso de la brecha "socio-digital": durante la vigencia del primer estado de alarma en España el 34\% de los hogares destacaban la bajada del rendimiento escolar de sus hijos/as: el 17\% de ellos lo achacaban a la falta de dispositivos adecuados y otro $17 \%$ a la necesidad de un refuerzo educativo que no se podía prestar electrónicamente ${ }^{85}$.

83 El art.14 Ley 34/2015 reconoce a las personas físicas el derecho a elegir relacionarse con la Administración de forma analógica o digital. Por el contrario, estarán obligados a interactuar por vía telemática las entidades (tengan o no personalidad jurídica), los profesionales de colegiación necesaria o los empleados públicos. Sin embargo, en su tercer apartado abre la posibilidad de extender reglamentariamente la obligación a personas físicas siempre que quede acreditado que... tienen acceso y disponibilidad de los medios electrónicos necesarios. Desde la perspectiva del principio de la igualdad material la dificultad residiría en cómo garantizar de forma efectiva esa disponibilidad.

${ }^{84}$ El $42 \%$ de los hogares en situación de exclusión social grave declaran no tener las competencias necesarias para realizar trámites administrativos en internet. Ver FOESSA, Distancia social y derecho al cuidado 2020. Análisis y perspectivas, Caritas, Madrid, 2020.

https://caritas-web.s3.amazonaws.com/main-files/uploads/2020/06/C\% C3\% 81RITAS-analisis-y-persectivas-digital-00000002.pdf(07/05/2021).

85 FOESSA, Distancia social y derecho al cuidado 2020 ... cit., p. 25.

ISSN: 1133-0937

DOI: https://doi.org/10.20318/dyl.2022.6520
DERECHOS Y LIBERTADES

Número 46, Época II, enero 2022, pp. 241-272 
En el anterior apartado dimos cuenta de la existencia de iniciativas en la dirección de consolidar el voto electrónico. Esta digitalización del derecho de sufragio ofrece oportunidades y riesgos para el principio de igualdad. Por una parte, puede facilitar la participación de colectivos que se han visto seriamente perjudicados en el ejercicio de su derecho al voto por las trabas burocráticas, destacando entre ellos las personas españolas residentes en el exterior $^{86}$. Por el contrario, una apuesta demasiado apresurada por el sufragio electrónico que dejara sin efecto las vías analógicas para ejercerlo podría impactar negativamente en la participación de los sectores más afectados por la brecha digital, por lo que hay autores que defienden la necesidad de que se mantengan su voluntariedad y la disponibilidad de las fórmulas tradicionales ${ }^{87}$. Si al nexo directo existente entre riesgo de pobreza y abstención electoral $^{88}$ le unimos el vínculo entre exclusión social y brecha digital, con seguridad se generará una mayor precarización de la participación política de las capas sociales más vulnerables.

Por lo tanto, en la erradicación de la brecha digital deben confluir estrategias multidisciplinares, que combinen la lucha contra la exclusión social "de partida", la alfabetización digital y el garantizar el acceso a los instrumentos materiales imprescindibles para el ejercicio de los derechos fundamentales en el entorno digital ${ }^{89}$. De esta manera, se puede defender que la universalización del acceso a internet como una manifestación del mandato de promover la igualdad material del art. 9.2 CE, o como parte de la dimensión objetiva y prestacional de derechos fundamentales para los que se ha constituido en herramienta esencial (la libertad de información, p.ej.) ${ }^{90}$.

En el ámbito de la UE de forma temprana se tomaron iniciativas políticas de impulso de la inclusión digital de la ciudadanía europea, pero con un carácter mucho más declarativo que vinculante ${ }^{91}$. En España también se elabo-

86 Ya analizamos esta realidad en C. ARCE; "Derecho de sufragio, Administración y principio de igualdad", Revista de Deusto, núm. 66, vol. 2, 2018, pp. 249-280.

87 M.Á. PRESNO, “Premisas para la introducción del voto electrónico... cit., p. 294.

88 C. ARCE; “Derecho de sufragio, Administración... cit., pp. 272 y ss.

89 S. OLARTE “Brecha digital, pobreza y exclusión social...cit., pp. 294-295.

90 L. COTINO, "Las obligaciones del Estado: el nuevo derecho fundamental...cit. pp. 58-59.

91 Ver "eEurope - Una sociedad de la información para todos" (COM -1999-687) https:// eur-lex.europa.eu/legal-content/ES/TXT/HTML/? uri=LEGISSUM:124221Efrom=ES (07/05/2021) y el Plan de acción "eEurope 2002 - Impacto y prioridades" (COM -2001-140) https://eur-lex. europa.eu/legal-content/ES/TXT/?uri=LEGISSUM\%3Al24226a (07/05/2021). 
raron instrumentos coetáneos similares que igualmente tuvieron un escaso recorrido ${ }^{92}$.

En el año 2013 se aprobó por el Gobierno de España la Agenda Digital para España ${ }^{93}$, entre cuyos objetivos se encuentran garantizar la conectividad digital y promover la inclusión y alfabetización digital. En la Ley 9/2014 de Telecomunicaciones se acogieron algunos de los citados principios de la Agenda; su art.3 establece como objetivos de la norma, entre otros:

Promover el despliegue de redes y la prestación de servicios de comunicaciones electrónicas, fomentando la conectividad y...su acceso, en condiciones de igualdad y no discriminación / Defender los intereses de los usuarios, asegurando su derecho al acceso a los servicios de comunicaciones electrónicas en condiciones adecuadas de elección, precio y buena calidad... en particular a través de un acceso abierto a Internet. En la prestación de estos servicios deben salvaguardarse los imperativos constitucionales de no discriminación / Salvaguardar y proteger... las necesidades de grupos sociales específicos, las personas con discapacidad, las personas mayores, las personas en situación de dependencia y usuarios con necesidades sociales especiales, atendiendo a los principios de igualdad de oportunidades y no discriminación.

Dando continuidad a esta línea de acción en el año 2020 se aprobó el referido Plan España Digital 2025, que pretende alcanzar en 2025:

...una conectividad digital adecuada para el 100\% de la población, promoviendo la desaparición de la brecha digital entre zonas rurales y urbanas $(100 \%$ de la población con cobertura $100 \mathrm{Mbps}$ ) y un $80 \%$ de personas con competencias digitales básicas, de las que el $50 \%$ serán mujeres ${ }^{94}$.

Por supuesto consideramos un avance la existencia de los citados instrumentos político-normativos con esos objetivos declarados en materia de inclusión digital; lo que genera más incertidumbre es si hay opciones reales de concitar el consenso de voluntades político-presupuestarias imprescindible para ello, y lo que es más difícil aún, sostenerlo en el tiempo.

92 Plan de Acción INFO XXI (2001-2003): https://avancedigital.gob.es/programas-avance-digital/DescargasPrimerasIniciativas/2001-Plan-InfoXXI.pdf (07/05/2021)

93 https://avancedigital.gob.es/programas-avance-digital/agenda-digital/Paginas/agenda-digital-para-Espana.aspx $(07 / 05 / 2021)$.

${ }_{94}$ https://www.lamoncloa.gob.es/presidente/actividades/Documents/2020/230720Espa\%C3\%B1aDigital_2025.pdf(07/05/2021).

ISSN: 1133-0937

DOI: https://doi.org/10.20318/dyl.2022.6520
DERECHOS Y LIBERTADES

Número 46, Época II, enero 2022, pp. 241-272 


\section{CONCLUSIONES}

De todo lo expuesto hasta ahora, podemos concluir que la ciudadanía en la era digital precisa de una profunda revisión a diferentes niveles:

- Una reconfiguración de su dimensión subjetiva para conseguir una coexistencia pacífica entre el "yo analógico" y el "yo digital". Por una parte, será necesaria una "educación para la ciudadanía digital” con el objetivo de que el propio ciudadano se haga consciente de esa dicotomía y sus implicaciones, y por otra, habilitar las herramientas normativas para dar respuestas a los intereses, a veces contrapuestos, de ambas proyecciones del titular de la ciudadanía, y que también permitan controlar la "construcción de su identidad".

- En su plano objetivo, se impone el reconocimiento del acceso a internet como derecho subjetivo, tanto desde la igualdad formal (art. 14 $\mathrm{CE})$ para evitar la discriminación en el acceso, como desde la material (art. 9.2 CE), atendiendo al imprescindible contenido prestacional que debe tener este derecho. Valorando las dos vías utilizadas en el Derecho comparado (constitucionalización o reconocimiento por vía legal), dada la complejidad del sistema de reforma constitucional español, consideramos más viable la opción de la legislación ordinaria. En concreto, a través de la modificación de la Ley 9/2014 de Telecomunicaciones o introduciéndolo como complemento instrumental básico en la legislación orgánica que desarrolla los derechos fundamentales más concernidos (en la línea de lo que tímidamente apunta el art. 85 LOPD 2018).

- En cuanto a las nuevas herramientas formales y técnicas que afectan al ejercicio de la ciudadanía (como los analizados Big data, perfiles y algoritmos), concluimos que su nivel de afectación a los derechos fundamentales no permite dejarlas en manos de la autorregulación de los agentes privados que operan en el sector de las nuevas tecnologías. En este sentido, la propuesta de aplicarles los principios y procedimientos básicos de la producción normativa "analógica" nos parece pertinente. También entendemos que deben ser acotadas las amplísimas excepciones que vacían de contenido práctico a la prohibición del art. 22 Reglamento (UE) 2016/679 de ser sometido a decisiones que afecten a los derechos del ciudadano basadas exclusivamente en el tratamiento automatizado. 
- Vinculado con lo anterior, la regla general del consentimiento informado fijada por el Reglamento (UE) 2016/679 y la LOPD 2018 ha mostrado su ineficacia para la protección material de derechos fundamentales como la intimidad, honor, propia imagen o la protección de datos en el contexto digital. El Estado debe tomar una actitud regulatoria proactiva de las condiciones contractuales que rigen las relaciones entre la ciudadanía y las grandes compañías que manejan de forma masiva datos personales. El camino recorrido en la protección de los consumidores frente a las condiciones generales de la contratación, contratos de adhesión o cláusulas abusivas puede ser de gran utilidad en esta materia.

- En lo concerniente a las libertades de expresión e información, nos parece alarmante la inacción estatal y la cesión de la toma de decisiones que afectan a estos derechos fundamentales a las empresas privadas dominantes en el mundo digital. En especial reclamamos la intervención pública a nivel estatal y de la UE para garantizar la neutralidad de la red. Por otra parte, si cualquier limitación de estas libertades llevadas a cabo por los poderes públicos, incluso cuando se fundamentan en la protección de otros derechos fundamentales, deben ser desarrolladas de una forma extraordinariamente restrictiva para evitar los riesgos de censura, consideramos que la imposición directa o indirecta de estas limitaciones por agentes privados es simplemente inaceptable. Sin embargo, funciones similares están siendo ejercidas por proveedores de servicios en la red.

- Somos conscientes del grave riesgo que suponen para el correcto funcionamiento de las instituciones democráticas la desinformación y las "noticias falsas" que se propagan a través de internet. En la lucha por neutralizar sus efectos entendemos que hay que poner el acento en la citada "educación para la ciudadanía digital" y el "fact checking", siendo inicialmente refractarios a medidas limitativas de las libertades de expresión e información en la red.

- Por último, es imprescindible un abordaje holístico de la "brecha digital". No se puede desconocer su conexión directa con la exclusión social que hunde sus raíces en el periodo analógico, que cuestiona la dimensión material de la ciudadanía desde sus orígenes. Por lo tanto, junto al reconocimiento del acceso a las herramientas tecnológicas imprescindibles para el ejercicio de la ciudadanía en la era digital como derecho subjetivo, es necesario paliar las carencias de 
competencias para su adecuada utilización que tienen las capas sociales más vulnerables. Y mientras lo anterior se alcanza, hay que mantener los cauces analógicos de los derechos de los ciudadanos y de relaciones con las administraciones; una apresurada digitalización masiva de estos aspectos como la que estamos viviendo durante la pandemia del coronavirus está acentuando la exclusión de los sectores de la población más empobrecidos.

\author{
Carlos Arce JimÉnez \\ Área de Derecho Constitucional \\ Departamento de Derecho Público y Económico \\ Universidad de Córdoba \\ Facultad de Derecho y CCEE. \\ Plaza de Puerta Nueva s/n, \\ 14002 Córdoba. \\ E-mail:carce@uco.es
}

